\title{
Patterns, causes and consequences of regional variation in the ecology and life history of a reef fish
}

\begin{abstract}
Many species vary in their ecology across their geographic ranges in response to gradients in environmental conditions. Such variation, which can influence life history traits and subsequent demography of populations, usually occurs over large spatial scales. However, describing and understanding the causes of such variation is difficult precisely because it occurs over such large spatial scales. In this study, we document spatial variation in the ecology of a common reef fish, Stegastes beebei, in the Galápagos Islands and test a number of potential causal mechanisms. The pattern resembles that seen in latitudinal variation: individuals are larger, occur in higher densities, and live longer in the coldest region of the islands than those in the warmest region. However, in this system, demography varies among regional populations separated by $<150 \mathrm{~km}$. Preferred nutritious algae are more available in the cold region and comprise a greater proportion of the diet of fish in this region. Per gram reproductive effort appears to be strongly related to temperature, despite differences in the gross magnitude and timing of reproduction in different regions. A model of reproductive output suggests that fish in the warmest region are allocating a greater proportion of available energy to reproduction, resulting in apparent regional life history tradeoffs. Our data suggest that regional demographic differences in $S$. beebei may be driven by a combination of variation in food availability and an environmentally mediated life history tradeoff.
\end{abstract}

Communicated by Craig Osenberg

B. I. Ruttenberg $(\bowtie) \cdot$ A. J. Haupt · R. R. Warner Department of Ecology, Evolution and Marine Biology, University of California, Santa Barbara, 93106 CA, USA E-mail: ruttenbe@lifesci.ucsb.edu

Tel.: + 1-805-8958486

Fax: + 1-805-5095375

A. I. Chiriboga

Charles Darwin Research Station,

Santa Cruz, Galàpagos, Ecuador

\section{Introduction}

Many species vary in their ecology across their geographic ranges in response to gradients in environmental conditions (e.g. Brown 1995 and references therein). This ecological variation can affect life history traits and demographics of populations, and occurs over large spatial scales because environmental gradients are often associated with latitude (Boyce 1978; Choat and Robertson 2002; James 1970). Describing such large-scale patterns in ecological variation and elucidating the processes that create them have a number of important implications for ecology, evolutionary biology, and natural resource management. Ecological variation may allow us to examine life history tradeoffs as organisms in different environments allocate differing amounts of energy to maintenance, growth and reproduction, and reliable estimates of these demographic parameters are required to manage exploited populations. In addition, understanding how organisms respond to natural environmental variation, such as temperature, will help us to predict population and community level changes as global temperatures are predicted to rise over the next century (Sanford 1999).

Most of the previous work examining patterns and processes of intraspecific variation over large scales has been done in temperate regions (e.g. Blanchette et al. 2002; Brown 1995; James 1970; Johnston and Selander 1973), and little work has explored these patterns in the tropics (but see Graves 1991). However, researchers have begun to examine large-scale patterns in tropical reef fishes. Recent studies of the demography of tropical reef fishes have revealed that many species are longer lived than previously believed (Choat and Axe 1996) and 
additional work has found significant demographic variation across the ranges of other species (Choat and Robertson 2002; Choat et al. 2003; Gust et al. 2002; Meekan et al. 2001). Despite these advances, none of this work has explicitly addressed potential causal mechanisms with data.

Meekan et al. (2001) speculate that demographic changes among populations of two Eastern Pacific damselfishes may be due to a combination of predation and an unspecified "edge of range" effect. Choat et al. (2003) found that higher latitude populations of a Caribbean parrotfish were generally older and larger, but confounds from fishing pressure precluded any inferences about causation. Gust and colleagues (Gust et al. 2002, 2001) suggest that density-dependent growth, mediated by recruitment and habitat quality, may be responsible for demographic variation between mid shelf and outer shelf reefs on the Great Barrier Reef, but they were unable to evaluate these hypotheses. Choat and Robertson (2002) found a negative relationship between maximum age and mean annual sea surface temperature (SST) for a number of scarids and acanthurids, noting that lower temperatures may lower growth rates and increase longevity. They suggest that changes in reproductive patterns in different thermal environments may drive selection for different lifespans.

The goal of this study is to describe patterns of regional ecological and demographic variability across the range of the white-tailed damselfish (Stegastes beebei) in the Galápagos Islands and critically evaluate a number of potential causal mechanisms that may create these patterns. The Galápagos Archipelago is an ideal system in which to study regional ecological variation because strong environmental gradients exist over relatively small spatial scales. For example, SST can vary $5^{\circ} \mathrm{C}$ or more over only $150 \mathrm{~km}$, whereas similar changes in SST in the tropics usually occur over latitudinal distances of $600-1,000 \mathrm{~km}$. Because the archipelago spans only $3^{\circ}$ of latitude directly on the equator, some of the factors that covary with latitude and have been found to influence local ecology, such as variation in season length and day length (e.g. Conover and Present 1990), do not affect Galápagos.

We use size structure, population density, and size-atage data to describe regional patterns of ecological and demographic variability. Qualitatively, our results are similar to those of many of the studies cited above. Individuals tend to be larger and longer lived in regions of the islands where water is colder and smaller where water is warmer. However, demographic differences among regions of the archipelago are larger than those detected in other systems and occur over much smaller spatial scales. We focus on two mechanisms that appear to be the main drivers of demographic variation in $S$. beebei: (1) regional variability in food availability and/or quality, and (2) temperature-mediated tradeoffs between growth and reproduction.

\section{Materials and methods}

\section{Physical setting}

The Galápagos Islands straddle the equator $\left(1.5^{\circ} \mathrm{N}-\right.$ $1.5^{\circ} \mathrm{S}$ and $89^{\circ}-92^{\circ} \mathrm{W}$ ) at the confluence of three major oceanic currents. The Humboldt Current brings cool water northwards from the coast of Peru, the Panamá Current brings warm water south from the Gulf of $\mathrm{Pa}$ namá, and the eastward-flowing Cromwell Current (or Equatorial Undercurrent) emerges at the western islands, upwelling cold, nutrient-rich water from depth (Glynn and Wellington 1983; Houvenaghel 1984). These three currents create a series of hydrogeographic regions within the islands that vary in both temperature and productivity (Palacios 2002). Following Wellington et al. (2001), we classify the islands into four regions for this study: (1) North, dominated by Panamá Current water where water temperatures are warmest; (2) West, dominated by Cromwell Current water where temperatures are coldest; (3) South, dominated by Humboldt Current water where temperatures are cool but warmer than the West; and (4) Central, a mixed region where temperatures are similar to (if slightly warmer than) the South (Fig. 1). Islands in different regions are separated by as little as $10-20 \mathrm{~km}$ and by no more than $150 \mathrm{~km}$. Strong seasonality also affects the entire archipelago, with changes in water temperature between the warm season (December-May) and the cold season (June-November) of up to $8^{\circ} \mathrm{C}$ (Houvenaghel 1984; Wellington et al. 2001).

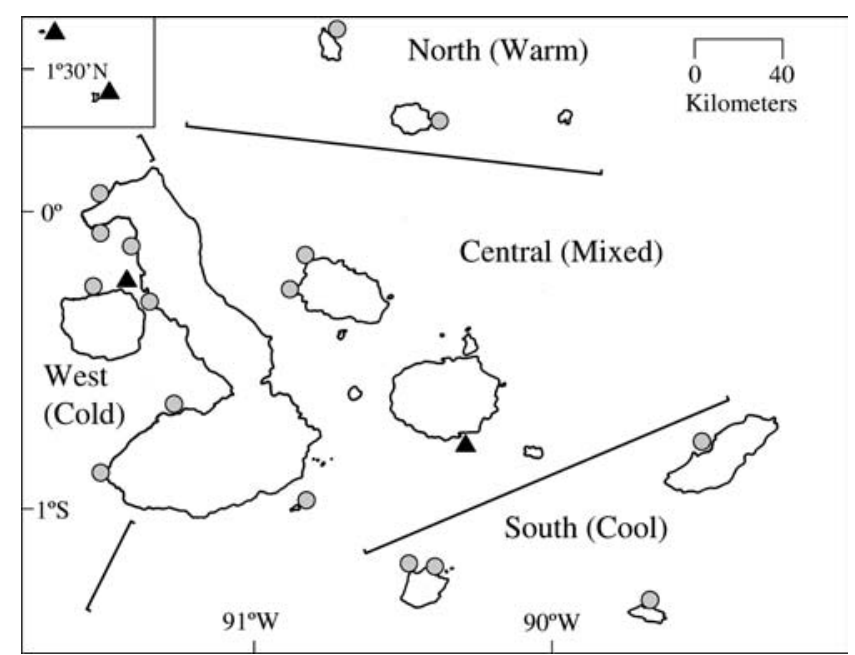

Fig. 1 Map of Galápagos showing four temperature regions (North, Central, South, West). Shaded circles represent sites where adults were collected, black triangles represent sites where reproduction was monitored and where adults were collected. The two islands in the inset are shown at the correct longitude but are centered at $1^{\circ} 30^{\prime} \mathrm{N}$ 
Study species, collections, and sample processing

Stegastes beebei is a territorial herbivore abundant on shallow rocky reefs in all regions of Galápagos. To quantify regional demographic patterns, we collected 318 individuals from 20 sites in all four regions of the islands using hand spears from 7 June 2002 to 12 July 2002 (see Fig. 1 for site locations). Individuals were targeted haphazardly, frozen immediately after collection, and thawed and processed at the Charles Darwin Research Station (CDRS). We measured standard length (SL) and total weight. The stomach was removed and its contents sorted to functional group for algae (Steneck and Dethier 1994) or the lowest taxonomic level possible for other items. All items were weighed wet $( \pm 0.001 \mathrm{~g})$. Sagittal otoliths were removed, cleaned, and stored dry for age-based demographic analysis. Twenty additional samples were collected from the West and Central regions between 28 June 2003 and 12 July 2003 for otoliths only.

A subset of $\sim 250$ otoliths from all four regions was selected for aging. Previous work has validated annuli in $S$. beebei using checks from strong El Niño events (Meekan et al. 1999). Procedures for processing otolith samples generally followed those of Meekan et al. (2001, 1999). The right sagitta from each sample was embedded in a resin block and sectioned transversely using a lowspeed saw. The section was mounted on a glass slide using thermoplastic glue $\left(\right.$ Crystalbond $\left.^{\mathrm{TM}}\right)$, polished using $30 \mu \mathrm{m}$ lapping film, and read under a compound microscope at $100 \times$ magnification using transmitted light. Two readers independently examined each sample. When counts did not agree, each reader reread the sample twice more. Eighteen otoliths for which counts did not agree after three readings were excluded. Sample sizes per region are detailed in Table 1 .

We generated regional growth curves using size-atage data fit to the von Bertalanffy growth function $(\mathrm{VBGF}): L_{t}=L_{\text {inf }}\left(1-\exp \left[-k\left(t-t_{0}\right)\right]\right)$, where $L_{t}$ is length at age $t, L_{\text {inf }}$ is mean asymptotic length, $k$ is a growth parameter that describes the rate at which the asymptotic length is reached, $t$ is the age in years, and $t_{0}$ is the theoretical age at which length is 0 . We constrained $t_{0}$ to -0.1 following the work of Meekan et al.
(2001) on S. beebei. The regional growth parameters were compared by plotting estimates of $L_{\text {inf }}$ and $k$ for each region along with $95 \%$ confidence intervals (Kimura 1980).

Mortality rates were estimated by plotting log-linear regressions of age-frequency data for each region. Because larger fish were targeted, age classes below the modal year class for each region were excluded (Ferreira and Russ 1992). Age class 2 was excluded from the Central, South, and West but included in the North. Slopes of mortality curves were compared using ANCOVA (Zar 1999). While these statistical techniques assume constant recruitment rates, they are robust to moderately large variation in recruitment (Meekan et al. 2001).

Because our collections were biased towards larger individuals, our data give us a better estimate of the largest and oldest individuals in a population than the true population means. To adjust for this, we calculated means of the top quartile in each region for size (SL in $\mathrm{mm}$ ) and age (in years), following Choat and Robertson (2002).

\section{Surveys}

A single diver conducted all surveys to quantify regional differences in population density and reproductive effort. Adult densities were surveyed in $30 \times 4-\mathrm{m}$ belt transects haphazardly placed at $\sim 5-6 \mathrm{~m}$ depth. Surveys were conducted both at the time adults were collected and opportunistically on other field trips between March 2002 and July 2002. There was no effect of census date so all surveys from a given site were pooled. Sampling effort is detailed in Table 1. Average biomass was computed for each site using site-specific estimates of adult weight from the collections, multiplied by mean density at that site.

Egg production was quantified using three $30 \times 4 \mathrm{~m}$ permanent transects at a single site in each of the Central and West regions. Because visits to the remote North were infrequent, we used three haphazardly placed $30 \times 4$ $\mathrm{m}$ transects there and pooled data across three sites (Table 1). We measured two perpendicular diameters for

Table 1 Sample sizes by region for collections of $S$. beebei, otolith aging data, and sampling effort for adult density surveys and the CDRS monitoring studies from which we extracted densities of potential predators of and benthic cover of potential food items of $S$. beebei

\begin{tabular}{|c|c|c|c|c|c|c|c|c|c|}
\hline \multirow[b]{2}{*}{ Region } & \multicolumn{2}{|c|}{ Adult collections } & \multirow{2}{*}{$\begin{array}{l}\text { Reproductive output surveys } \\
\text { No. of times surveyed }\end{array}$} & \multicolumn{2}{|c|}{$\begin{array}{l}\text { Adult density } \\
\text { surveys }\end{array}$} & \multicolumn{2}{|c|}{$\begin{array}{l}\text { Predator density } \\
\text { surveys }{ }^{b}\end{array}$} & \multicolumn{2}{|l|}{ Benthic cover surveys } \\
\hline & No. collected & No. aged & & Transects & Sites & Transects & Sites & Transects (quadrats) & Sites \\
\hline North & 98 & 60 & 3 & 40 & 11 & 22 & 9 & $10(100)$ & 9 \\
\hline Central & 76 & 48 & 15 & 16 & 5 & 3 & 3 & $2(20)$ & 2 \\
\hline South & 46 & 28 & 0 & 3 & 3 & 105 & 25 & $46(460)$ & 24 \\
\hline West & 116 & 89 & 9 & 41 & 15 & 27 & 15 & $16(160)$ & 16 \\
\hline
\end{tabular}

${ }^{a}$ All surveys of reproduction conducted in 2002 between: 3 April and 25 July (North); 23 March and 6 August (Central); and 3 March and 23 July (West)

${ }^{b}$ Predators include larger members of the families Cirrhitidae, Muraenidae, Scorpaenidae, and Serranidae 
each nest in each transect and calculated area using the formula for an oval $\left(\left[\mathrm{d}_{1} \mathrm{~d}_{2} \pi\right] / 4\right)$, using nest area as a proxy for egg number and egg production (Doherty 1983; Robertson et al. 1988). Area for all nests in a given transect was summed for that transect to generate a value of total area of eggs produced per transect (in units of $\mathrm{cm}^{2}$ eggs/120 $\mathrm{m}^{2}$ of reef). Because both adult biomass and gross production varied among regions, production was standardized by dividing gross egg production by a site-specific estimate of adult biomass, resulting in a scaled population-level measure of egg production per unit of adult biomass (in units of $\mathrm{cm}^{2}$ of eggs/g of adult tissue). Since fecundity generally scales isometrically with mass in fishes (Wootton 1990), this standardized measure of reproduction allows us to compare the per $\mathrm{g}$ reproduction across populations that may vary in mean body size.

However, our measure of egg production is actually a measure of egg standing stock. Estimates of production might change if egg development rates increase with temperature, as has been shown for some reef fishes (Thresher 1984). Asoh and Yoshikawa (2002) found that egg development time for a tropical damselfish decreased linearly by $3.3 \%$ per ${ }^{\circ} \mathrm{C}$ over a $3^{\circ} \mathrm{C}$ increase in temperature. We used this relationship to adjust scaled egg production values, based on the temperature at each site at the time of sampling (see below), using $20.5^{\circ} \mathrm{C}$ as our baseline temperature, as it was the lowest temperature at which egg production was non-zero. Ignoring this correction (using uncorrected scaled egg counts) gave the same qualitative conclusions and has virtually no effect on the quantitative results. Thus, our results seem fairly robust to assumptions about temperature-dependent egg development rates.

We then regressed this scaled, temperature-corrected measure of egg production (hereafter referred to as "scaled production") against temperature from that site. Temperature was determined using a 2 -week moving average from temperature loggers placed at each site (see below). Surveys of egg production were conducted in each of the three regions opportunistically when trips to these areas were available (Table 1). Sampling in all regions was distributed haphazardly with respect to lunar phase.

Abundance of potential predators of $S$. beebei and benthic cover was calculated from multiple sites in all regions using unpublished data from CDRS monitoring surveys. CDRS surveys of fish densities used $50 \times 10-\mathrm{m}$ transects at 6-m depth (see Edgar et al. 2004 for a description of methods). Surveys were conducted from May 2001 to May 2003 at 52 sites on eight different islands, but most site-date combinations included only a single transect. We extracted abundance data for potential predators of adult $S$. beebei (larger members of the families Cirrhitidae, Muraenidae, Scorpaenidae, and Serranidae) from 157 transects (Table 1).

Benthic cover was estimated using $0.5 \times 0.5-\mathrm{m}$ quadrats, subdivided every $5 \mathrm{~cm}$ by perpendicularly interlaced cords in each orientation. The dominant sessile organism or substrate type below each intersection of cords ( $\mathrm{n}=81$ per quadrat) was recorded. Quadrats were placed every $5 \mathrm{~m}$ along a $50-\mathrm{m}$ transect at 6-m depth for a total of 10 quadrats per transect (see Banks and Wiedenfeld 2003 for a description of methods). Only one transect was surveyed per site at a given time. We only analysed data from the cold season in 2002 (between June and October), because we made collections of adult $S$. beebei during this time. Data were collected from 51 sites around 8 islands, but most sites were visited only once during this interval (Table 1).

\section{Physical data}

To examine correlations between demographic patterns and physical data, we collected sea surface chlorophyll a and temperature data. We obtained satellite-derived chlorophyll a concentrations for the $3 \times 3-\mathrm{km}$ grid surrounding each of the reproduction study sites from the SeaWiFS project for the period from January-September 2002 (D. Palacios, unpublished data).

Temperature loggers (Tidbits, Onset Computer Corp.) were deployed at 6-m depth at the sites where we monitored reproduction in the Central and West and at Wolf Island in the North (the southern of the two most northerly islands; Fig. 1) between March 2002 and July 2003. However, temperature records from our loggers at Wolf were only retrieved from 5 May 2002 through 29 July 2002. Additional unpublished temperature records (also from loggers deployed near to ours at the same sites at 8-m depth; Fig. 1) were provided by the CDRS for the North and West from 2001. While there was no temporal overlap in our temperature records with those of the CDRS, concurrent temperature data from $6 \mathrm{~m}$ and $12 \mathrm{~m}$ differ by an average of only $0.65^{\circ} \mathrm{C}$, so differences between $6 \mathrm{~m}$ and $8 \mathrm{~m}$ are likely to be much smaller than this. We regressed scaled reproductive output against temperature using our temperature records.

We then used the resulting regression model to predict daily and cumulative annual egg production for the North and West from 2001 using the CDRS temperature data and from the Central and West from 2002 using our temperature records. For each day in each region, we used the 14-day moving average ending on that day to predict scaled reproductive output for that day, and repeated this process for each day of the year. To estimate daily variation throughout the year, we used Monte Carlo simulations incorporating residuals from the regression model drawn at random (10,000 iterations). To calculate standard error, effective sample size was estimated by dividing the number of sample dates by the decorrelation time scale of each annual temperature time series, estimated using the lag-1 autocorrelation (Chatfield 1992). Per capita estimates of daily pro- 
duction were estimated using the same procedure as above, adding a term with the mean adult size and variation at each site.

\section{Results}

\section{Regional demographic variation}

Body size, age, population density, and mortality rate of $S$. beebei varied significantly among regions within the archipelago, particularly between the North (warm) and West (cold). Top quartile size, top quartile age, and average densities of adults were greater in the West than in the North (Fig. 2), and biomass was approximately five-fold greater in the West than in the North (Fig. 2c). Size-at-age curves varied regionally (Fig. 3a), and VBGF parameters differed among regions. The growth parameter $k$ was largest in the North while the asymptotic length $L_{\text {inf }}$ was largest in the West (Table 2). Slopes of mortality curves differed significantly among regions (ANCOVA: $F=5.85 ; \mathrm{df}=3,42 ; P=0.002$ ); mortality rates were higher in the North than in the West or Central (Fig. 3b; Table 2). Values for most of the abovementioned traits in the Central and South were similar to each other and generally intermediate between the West and North.

Productivity, benthic cover, and gut contents

Productivity (chlorophyll-a) was highest in the West and up to an order of magnitude greater than in the North, depending on the season (Table 3). Abundance of benthic algae, particularly the nutritious fleshy green algae Ulva sp. (Nagy and Shoemaker 1984; Rubenstein and Wikelski 2003), generally reflected regional productivity and was much higher in the West than the North (Fig. 4a). In general, regional gut contents reflected regional food availability (Fig. 4). Gut content data show that fish from the West were feeding primarily on Ulva, while those from the North were eating a variety of other foods (Fig. 4b). Ulva occupied between 16\% and $38 \%$ of space in the Central, South, and West and comprised between $27 \%$ and $77 \%$ of diets in these regions. In the North, Ulva occupied $<0.5 \%$ of available space and only $2 \%$ of the diet in that region. Red filamentous algae, another nutritious form (Nagy and Shoemaker 1984; Rubenstein and Wikelski 2003), occupied between $3 \%$ and $10 \%$ of available space in each region and comprised between $6 \%$ and $43 \%$ of the diets in all regions (Fig. 4).

\section{Reproductive output and energy allocation}

Gross egg production differed among regions; maximum egg production was nearly $4,000 \mathrm{~cm}^{2} /$ transect in the West, $1,700 \mathrm{~cm}^{2} /$ transect in the Central, and less than
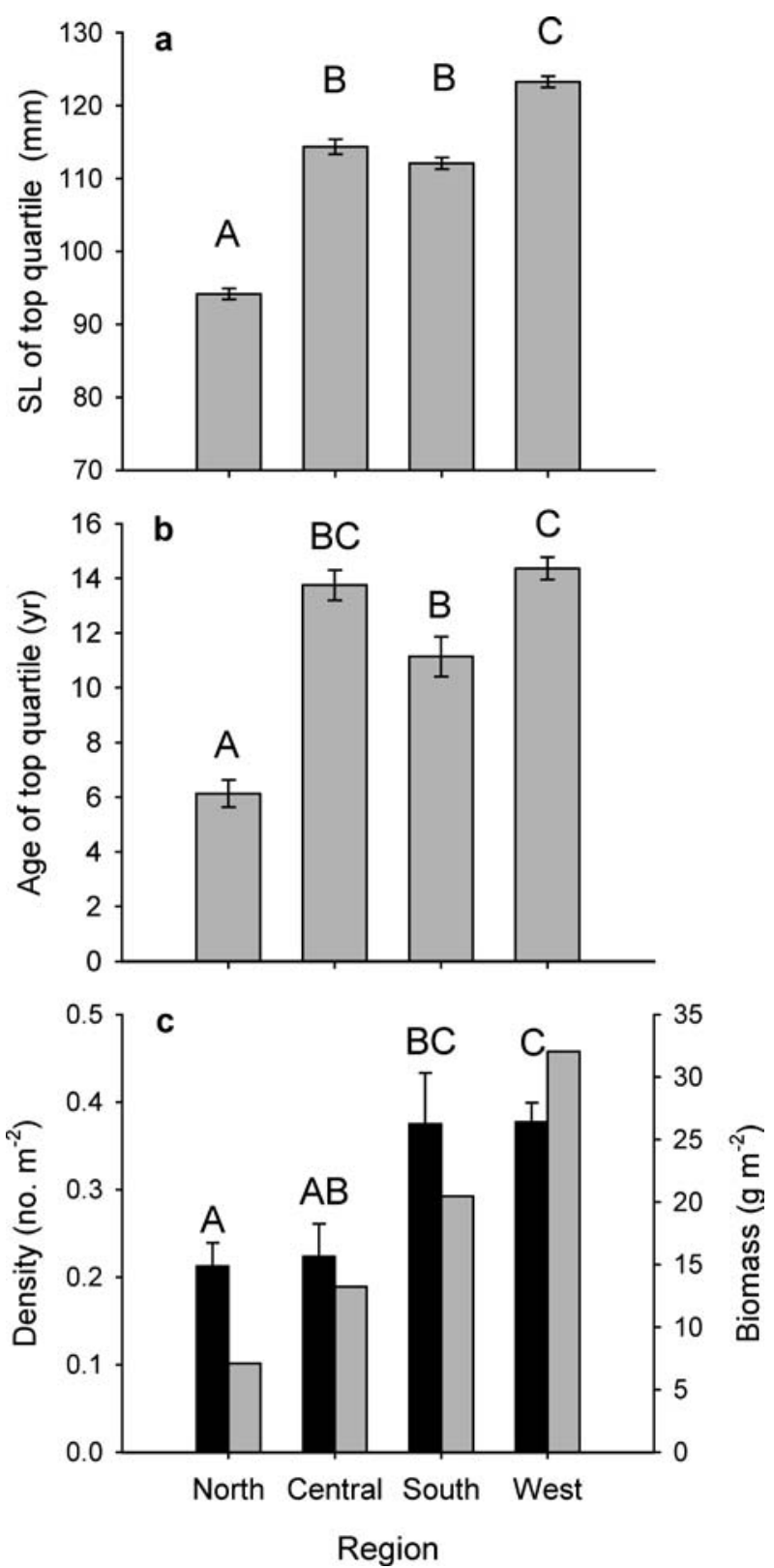

Fig. 2 Mean $( \pm 1 \mathrm{SE})$ a SL and $\mathbf{b}$ age of the top quartile of Stegastes beebei collected from each region. Regional means differed significantly (SL: $F=284.6 ; \mathrm{df}=3,74 ; P<0.0001$; age: $F=60.8 ; \mathrm{df}=3,55 ; P<0.0001$ ). c Mean density ( $\pm 1 \mathrm{SE}$ ) (fully shaded box) and mean biomass (grey shaded box) of $S$. beebei by region. Regional densities differed significantly $(F=7.16$; $\mathrm{df}=3,34$; $P<0.0001)$. For all plots, letters above bars denote significantly different groups as determined by Tukey's HSD post hoc tests; no tests were calculated for biomass

$400 \mathrm{~cm}^{2} /$ transect in the North. However, temperaturecorrected scaled egg production (see Methods) greatly reduced inter-regional variability in egg production (maximum values in the North, Central, and West were $0.54 \mathrm{~cm}^{2} / \mathrm{g}, 0.99 \mathrm{~cm}^{2} / \mathrm{g}$, and $0.93 \mathrm{~cm}^{2} / \mathrm{g}$ respectively). The quadratic regression between scaled reproductive output and ambient temperature $(F=23.6 ; \mathrm{df}=2,23$; 

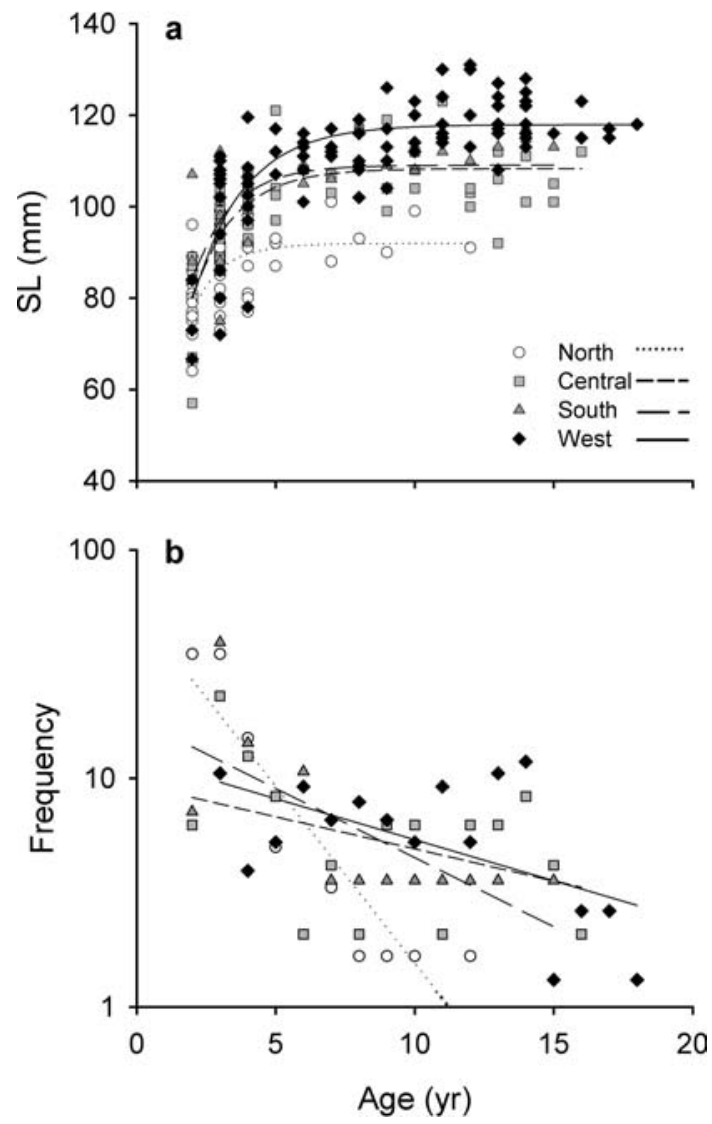

Fig. 3 a Size-at-age data with fitted von Bertalanffy growth functions (VBGF) for $S$. beebei, plotted by region. Curves were fit to the function: $L_{t}=L_{\mathrm{inf}}\left(1-\exp \left[-k\left(t-t_{0}\right)\right]\right)$, where $L_{t}$ is length at age $t, L_{\text {inf }}$ is the mean asymptotic length, $k$ describes the rate at which $L_{\text {inf }}$ is reached, and $t_{0}$ is a hypothetical age when length $=0$. b Regional mortality curves for $S$. beebei. Symbols follow Fig. 3a; see Table 2 for regression statistics

Table 2 Mortality and von Bertelanffy growth function (VBGF) parameters for $S$. beebei by region. Slopes of mortality curves derived from log-linear regression of age frequency data, excluding year classes to the left of the modal year class. Values for individual regressions for which $P<0.05$ are in bold. VBGF parameters derived from size-at-age data shown in Fig. 3a. Values for the slope of mortality curves and VBGF parameters $\pm 1 \mathrm{SE}$

\begin{tabular}{lllllll}
\hline \multirow{2}{*}{ Region } & \multicolumn{2}{l}{ Mortality } & & & \multicolumn{2}{l}{ VBGF parameters } \\
\cline { 2 - 3 } \cline { 6 - 7 } & Slope & $P$ & $R^{2}$ & & $K$ & \multicolumn{2}{l}{$L_{\text {inf }}$} \\
\hline North & $-0.303 \pm 0.07$ & $\mathbf{0 . 0 0 3}$ & 0.635 & & $1.01 \pm 0.10$ & $89.7 \pm 1.7$ \\
Central & $-0.065 \pm 0.03$ & 0.112 & 0.197 & & $0.94 \pm 0.13$ & $107.3 \pm 1.4$ \\
South & $-0.129 \pm 0.06$ & 0.075 & 0.261 & & $0.74 \pm 0.05$ & $109.5 \pm 1.4$ \\
West & $-0.063 \pm 0.02$ & $\mathbf{0 . 0 3 1}$ & 0.292 & & $0.61 \pm 0.06$ & $116.9 \pm 1.0$ \\
\hline
\end{tabular}

$\left.P<0.0001 ; \quad r^{2}=0.69\right)$ yielded a calculated optimum temperature for egg production of $24^{\circ} \mathrm{C}$ (Fig. 5).

Using the regression model and year-long temperature records (Table 3 ), we predicted daily and cumulative annual egg production for the North, Central, and West (no temperature records were available for the South). The resulting model of regional reproductive output shows that mean daily egg production per unit biomass is greater in the North than in the West (Fig. 6a), but because individuals are so much larger in the West, per capita daily reproduction is still higher there (Fig. 6b).

\section{Discussion}

The regional demographic differences among populations of $S$. beebei in the Galápagos Islands that we document are remarkable both in their magnitude and for the small spatial scales over which they occur. Top quartile size and mean densities were greatest in the cold West and lowest in the warm North, resulting in a fivefold difference in adult biomass between these regions. Top quartile age was also greatest in the West while mortality was highest in the North. Emerging research has shown that demographic variation among populations of reef fishes may be more common than once believed (Choat and Robertson 2002; Choat et al. 2003; Gust et al. 2001; Meekan et al. 2001), but even with this new perspective, the magnitude of regional differences are striking in this system. It is also noteworthy that with the exception of the work of Gust and colleagues (Gust et al. 2002, 2001), patterns of demographic variability have been observed over scales of $100 \mathrm{~s}-1,000 \mathrm{~s}$ of $\mathrm{km}$, as opposed to $<150 \mathrm{~km}$ in Galápagos.

A number of factors may singly or jointly influence patterns of regional demographic variation in $S$. beebei in Galápagos. However, our data suggest that demographic patterns are primarily the result of two key factors: (1) regional variation in productivity, food availability, and/or food quality and (2) temperaturemediated life history tradeoffs between growth/maintenance and reproduction.

\section{Productivity, food availability, and/or food quality}

Increased or improved food resources may influence demography by increasing growth rates, survivorship, or longevity, as previous work has shown for some reef fishes (Forrester 1990; Jones 1986; Jones and McCormick 2002). Lower temperatures and increased upwelling in the West are correlated with increased algal cover and presumably enhance food quality and quantity, which could result in increased growth and survivorship of $S$. beebei. This hypothesis assumes that in the West: (1) productivity is highest, (2) preferred food items are more abundant, and (3) diets are comprised primarily of preferred food items.

Productivity (chlorophyll a) is much higher in the West than the North (Table 3), and abundance of benthic algae, particularly Ulva sp. and red filamentous algae, mirrors variability in regional productivity (Fig. 4a). Data from other sources suggest that Ulva and red filamentous algae are the most nutritious groups of algae in Galápagos (Nagy and Shoemaker 1984; 
Table 3 Regional variation in chlorophyll-a $\left(\mathrm{mg} / \mathrm{m}^{3} \pm 1 \mathrm{SE}\right)$ and temperature. Chlorophyll data are from the SeaWiFS project (Palacios, unpublished data), $3 \times 3-\mathrm{km}$ grid nearest to the site of reproductive monitoring in each region during 2002 . Temperature data $\left({ }^{\circ} \mathrm{C}\right)$ are from our loggers (2002) and those of the CDRS (2001). Warm season data include February-April and cold season data include June-August. No data indicated by ND

\begin{tabular}{|c|c|c|c|c|c|c|}
\hline \multirow[t]{2}{*}{ Region } & \multicolumn{2}{|l|}{ Chlorophyll } & \multicolumn{4}{|l|}{ Temperature } \\
\hline & Warm & Cold & Warm 2001 & Cold 2001 & Warm 2002 & Cold 2002 \\
\hline North & $0.215 \pm 0.014$ & $0.254 \pm 0.015$ & 25.15 & 23.60 & ND & ND \\
\hline Central & $0.340 \pm 0.042$ & $0.368 \pm 0.037$ & ND & ND & 25.68 & 22.15 \\
\hline South & ND & ND & ND & ND & ND & ND \\
\hline
\end{tabular}

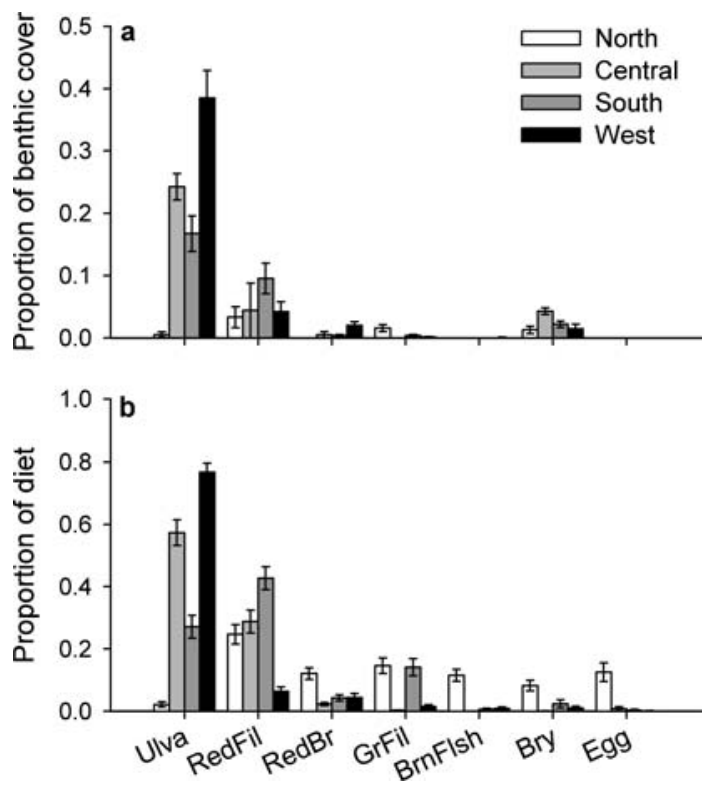

Fig. 4 a Benthic cover of items found in the diet and $\mathbf{b}$ gut contents of $S$. beebei by region: Ulva, Red filamentous algae (RedFil), Red branched algae (RedBr), Green filamentous algae (GrFil), Brown fleshy algae (BrnFlsh), Bryozoan (Bry), Eggs (includes fish and mollusk eggs). Error bars are $\pm 1 \mathrm{SE}$

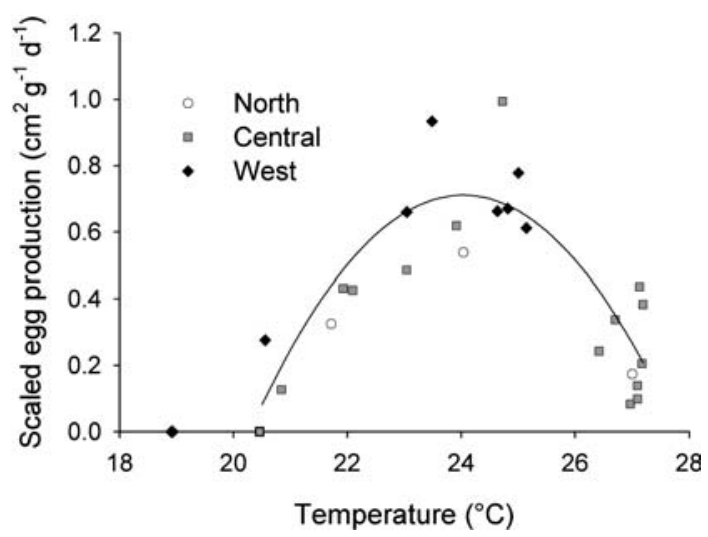

Fig. 5 Scaled egg production (measured as nest area) of S. beebei in three regions (North, Central, West) as a function of temperature. The regression is fit through all non-zero points
Rubenstein and Wikelski 2003; Wikelski and Wrege 2000). Gut content data show that these two groups are the most important in the diets of $S$. beebei. Optimal foraging theory predicts that animals in more productive habitats should have narrower diets (Krebs and Davies 1978; MacArthur and Pianka 1966; Werner and Hall 1974); when preferred food items are abundant, these items should dominate the diet. Fish from the West were primarily feeding on Ulva, while those from the North were eating a variety of other foods (Fig. 4b). Regional diversity indices of gut contents $\left(\mathrm{H}^{\prime}\right)$, one measure of diet breadth, are consistent with the hypothesis that food quality and/or abundance in the West are higher than in the North. Values for H' are highest in the North (1.80), moderate in the Central and South $(0.80$ and 1.29 , respectively), and lowest in the West (0.65). Since diets of $S$. beebei are comprised of similar items in all regions, narrower diets in the West suggest a greater abundance of preferred foods in that region, in this case, Ulva. Taken together, these data strongly support the hypothesis that differences in regional diet quality exist in Galápagos. These differences could contribute to regional shifts in size and age structure in $S$. beebei.

Patterns of reproduction and temperature-mediated life history tradeoffs

Spawning in many reef fishes follows a lunar cycle, but there are a number of species whose spawning appears to be aperiodic (Robertson 1991; Robertson et al. 1990). While the specific spawning cue for many of these species is unknown, some species may use temperature as a cue for the onset and termination of reproduction (Danilowicz 1995; Ochi 1985). Our data provide an example of a strong relationship between temperature and reproductive output (Fig. 5). Despite the fact that adult biomass differed by nearly five-fold among populations, temperature explained nearly $70 \%$ of the variance in reproductive output per unit biomass among three different populations that differed greatly in their gross magnitude and timing of reproduction. The temporal frequency of sampling at any one site was not sufficient to evaluate the effects of lunar phase on reproductive output explicitly, and we found no relationship between 
lunar phase and either raw or scaled reproductive output. There was a weak and non-significant relationship between lunar phase and the residuals of the scaled reproduction-temperature regression $(F=3.25 ; d f=1,23$; $\left.P=0.085 ; r^{2}=0.13\right)$. These results suggest that while lunar phase may have a weak influence on reproduction, temperature is the primary driver (or at least the primary cue) of reproductive output in $S$. beebei.

Modelled regional reproductive output strongly suggests that fish from the North are allocating more energy to reproduction per unit of adult biomass than those from the West (Fig. 6a). Increased reproductive activity in the North should reduce available energy for other needs, such as growth and maintenance. Disentangling cause from effect is difficult in this situation, because increased reproductive effort can be both a response to and a cause of increased mortality (Stearns 1992). However, populations in the North show a demography characteristic of high reproductive effort: higher egg production relative to biomass, slower growth, and lower survival. This tradeoff could result in lower growth rates and higher mortality in the North, especially given that food resources appear to be less abundant there.

These life history characteristics may influence per capita annual and lifetime reproduction. Despite the fact that fish from the North appear to be allocating more energy per unit biomass to egg production, predicted
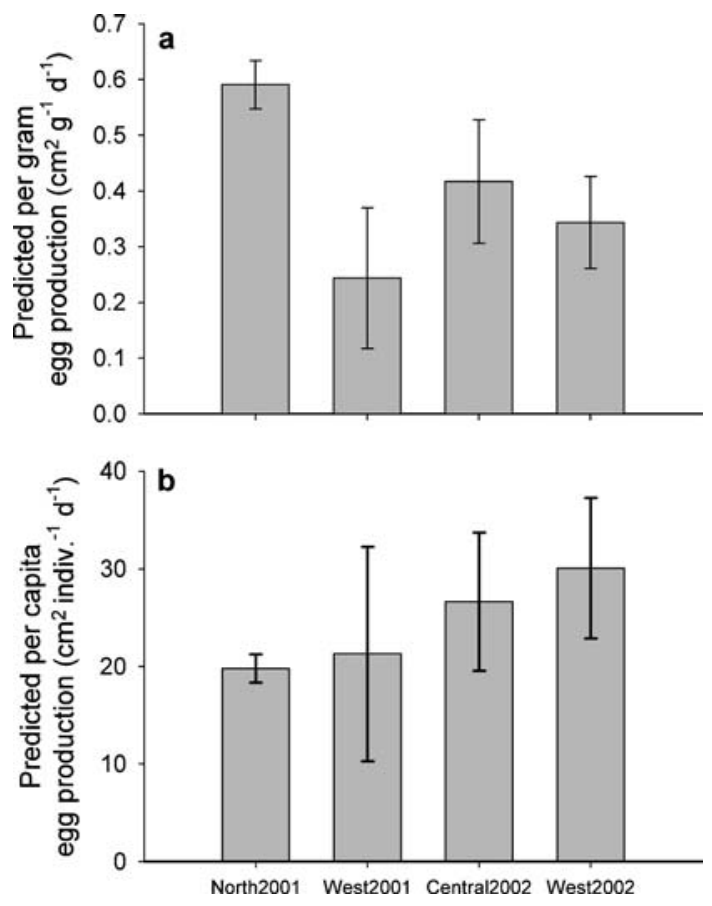

Fig. 6 Predicted daily egg production, measured as nest area, a per unit of adult biomass and $\mathbf{b}$ per capita for $S$. beebei. Values were generated using the equation for the regression line in fig. 5 as the function and mean daily temperature as the predictor. Error bars are \pm 1 SE. Note that temperature data are from 2001 and 2002 and were only available from the West for both years. No temperature data were available from the South daily per capita egg production is still higher in the West because adults there are so much larger than those in the North (Fig. 6b). Since average longevity is also greater in the West, differences in annual reproductive output should result in even greater differences in predicted lifetime reproductive output between the North and West. Different regional energy allocations may represent optimal responses to local conditions of productivity and mortality, but there is no expectation of full compensation in terms of lifetime reproductive success in different environments.

Other potential mechanisms and broader implications

A number of other mechanisms have been proposed to explain large-scale demographic shifts in coral reef fishes, including density-dependent growth or mortality, differing predator densities or predation rates, and direct effects of temperature. Gust et al. $(2002,2001)$ found that smaller and younger fish were living at highest densities on reefs with the lowest resource levels and suggested that density-dependent growth was responsible for demographic patterns. For such a mechanism to be operating in Galápagos, we would expect a similar inverse relationship between average adult size and local density. However, individuals in the West are both larger and living at higher densities than those in other regions (Fig. 2), suggesting that density-dependent growth is not responsible for regional demographic changes in $S$. beebei.

Differences in regional predator abundances or predation rates could also influence demographic patterns. Higher predation rates could lead to increased mortality and lower densities of adults (Hixon 1991; Hixon and Webster 2002; Jones and McCormick 2002) or less feeding time and slower growth due to increased vigilance (Holbrook and Schmitt 1988; Werner et al. 1983). Mortality rates calculated from log-linear age frequency data are higher in the North than the West (Fig. 3), and while the source of this mortality is unknown, some additional mortality in the North could be the result of reallocation of resources to reproduction (as opposed to maintenance). Using CDRS fish community survey data, we found that densities of potential predators of damselfish (e.g. morays and large groupers) do not differ between the North and West $(F=0.07 ; \quad \mathrm{df}=1,22$; $P=0.80$ ).

Finally, temperature may have a direct physiological influence on growth and mortality of $S$. beebei. It is generally accepted that terrestrial ectotherms tend to be larger in colder environments (Atkinson and Sibly 1997), but empirical evidence for fishes is equivocal (Belk and Houston 2002; Gilligan 1991) and the physiological mechanism that would drive such an effect is unclear. A combination of transplant and common garden experiments would provide the ideal test of the direct effects of temperature, but we were unable to perform these experiments. Thus, we cannot exclude the possibility 
that a temperature-driven physiological effect independently influences the demography of $S$. beebei in Galápagos.

In summary, our data demonstrate that latitudinal gradient-type patterns can exist in the tropics and may occur over small spatial scales. Evidence suggests that a combination of regional variation in food availability and environmentally mediated life history tradeoffs is driving the regional demographic patterns in S. beebei. However, it is uncertain whether the demographic differences we observe are plastic or adaptive responses to variable environments because we have no data on the population genetic structure or levels of connectivity among populations. These findings have implications for our understanding of population biology of both reef fishes and other marine organisms. Reproduction in a number of marine organisms appears to be linked to temperature, particularly for those populations at the edge of their ranges (Danilowicz 1995; Ochi 1985; Rubenstein and Wikelski 2003; Tyler and Stanton 1995). Populations in colder or more seasonal waters should have shorter reproductive seasons and may allocate less of their annual energy budgets to reproduction, resulting in larger, older animals in these populations. Data from a few studies using reef fishes (Choat and Robertson 2002; Choat et al. 2003; Meekan et al. 2001) support this hypothesis. While much more work is needed, environmentally mediated life history tradeoffs have the potential to explain widespread patterns in the demography of marine populations.

Acknowledgements We thank the staff of the Charles Darwin Research Station, the Galápagos National Park Service, the crew of the Beagle, and Ecoventura and the crew of the Sky Dancer for providing essential logistical support, laboratory space, and field assistance. Mil gracias a A. Astorga and y todos del Equipo Damisela. S. Banks and D. Palacios provided unpublished data. Thanks to P. Munday, W. White, S. Hamilton, J. Standish, C. Osenberg, and an anonymous reviewer for discussions and comments on drafts of this manuscript, and to W. White and B. Kinlan for assistance with programming and statistics. Funding was provided by the UC Regents, the International Society for Reef Studies-The Ocean Conservancy, the David and Lucille Packard Foundation, the Graduate Division of the University of California, Santa Barbara, the American Society of Ichthyologists and Herpetologists, the PADI Project AWARE Foundation, The Explorer's Club, and Sigma Xi. This paper represents contribution number 185 from the Partnership for Interdisciplinary Study of Coastal Oceans. Procedures used in this study complied with the laws of Ecuador and the United States.

\section{References}

Asoh K, Yoshikawa T (2002) The role of temperature and embryo development time in the diel timing of spawning in a coral-reef damselfish with high-frequency spawning synchrony. Environ Biol Fishes 64:379-392

Atkinson D, Sibly RM (1997) Why are organisms usually bigger in colder environments? Making sense of a life history puzzle. Trends Ecol Evol 12:235-239

Banks SA, Wiedenfeld D (2003) Ecological monitoring in the Galapagos Marine Reserve: an integrated approach. Fundación Charles Darwin, Santa Cruz, Galapagos
Belk MC, Houston DD (2002) Bergmann's rule in ectotherms: A test using freshwater fishes. Am Nat 160:803-808

Blanchette CA, Miner BG, Gaines SD (2002) Geographic variability in form, size and survival of Egregia menziesii around Point Conception, California. Mar Ecol Prog Ser 239:69-82

Boyce MS (1978) Climatic variability and body size variation in muskrats (Ondatra zibethicus) of North America. Oecologia $36: 1-19$

Brown JH (1995) Macroecology. University of Chicago Press, Chicago

Chatfield C (1992) The analysis of time series: an introduction, 4th edn. Chapman and Hall, London

Choat JH, Axe LM (1996) Growth and longevity in acanthurid fishes: an analysis of otolith increments. Mar Ecol Prog Ser 134:15-26

Choat JH, Robertson DR (2002) Age-based studies. In: Sale PF (ed) Coral reef fishes: dynamics and diversity in a complex ecosystem. Academic, San Diego, pp 57-80

Choat JH, Robertson DR, Ackerman JL, Posada JM (2003) An age-based demographic analysis of the Caribbean stoplight parrotfish Sparisoma viride. Mar Ecol Prog Ser 246:265-277

Conover DO, Present TMC (1990) Countergradient variation in growth-rate: compensation for length of the growing-season among Atlantic silversides from different latitudes. Oecologia 83:316-324

Danilowicz BS (1995) The role of temperature in spawning of the damselfish Dascyllus albisella. Bull Mar Sci 57:624-636

Doherty PJ (1983) Diel, lunar and seasonal rhythms in the reproduction of two tropical damselfishes: Pomacentrus flavicauda and Pomacentrus wardi. Mar Biol 75:215-224

Edgar GJ, Banks S, Farina JM, Calvopina M, Martinez C (2004) Regional biogeography of shallow reef fish and macro-invertebrate communities in the Galapagos archipelago. J Biogeogr 31:1107-1124

Ferreira BP, Russ GR (1992) Age, growth and mortality of the inshore coral trout Plectropomus maculatus (Pisces, Serranidae) from the central Great Barrier Reef, Australia. Aust J Mar Freshw Res 43:1301-1312

Forrester GE (1990) Factors influencing the juvenile demography of a coral reef fish. Ecology 71:1666-1681

Gilligan MR (1991) Bergmann ecogeographic trends among triplefin blennies (Teleostei, Tripterygiidae) in the Gulf of California, Mexico. Environ Biol Fishes 31:301-305

Glynn PW, Wellington GM (1983) Corals and coral reefs of the Galápagos Islands. University of California Press, Berkeley

Graves GR (1991) Bergmann's rule near the equator: latitudinal clines in body size of an Andean passerine bird. Proc Nat Acad Sci USA 88:2322-2325

Gust N, Choat JH, McCormick MI (2001) Spatial variability in reef fish distribution, abundance, size and biomass: A multiscale analysis. Mar Ecol Prog Ser 214:237-251

Gust N, Choat JH, Ackerman JL (2002) Demographic plasticity in tropical reef fishes. Mar Biol 140:1039-1051

Hixon MA (1991) Predation as a process structuring coral reef fish communities. In: Sale PF (ed) The ecology of fishes on coral reefs. Academic, San Diego, pp 475-508

Hixon MA, Webster MS (2002) Density dependence in reef fish populations. In: Sale PF (ed) Coral reef fishes: dynamics and diversity in a complex ecosystem. Academic, San Diego, pp 303-325

Holbrook SJ, Schmitt RJ (1988) Effects of predation risk on foraging behavior: mechanisms altering patch choice. J Exp Mar Biol Ecol 121:151-163

Houvenaghel GT (1984) Oceanographic setting of the Galápagos Islands. In: Perry R (ed) Key environments, Galápagos. Pergamon, Oxford, pp 43-54

James FC (1970) Geographic size variation in birds and its relationship to climate. Ecology 51:365-390

Johnston RF, Selander RK (1973) Evolution in house sparrow 3. Variation in size and sexual dimorphism in Europe and North and South America. Am Nat 107:373-390 
Jones GP (1986) Food availability affects growth in a coral-reef fish. Oecologia 70:136-139

Jones GP, McCormick MI (2002) Numerical and energetic processes in the ecology of coral reef fishes. In: Sale PF (ed) Coral reef fishes: dynamics and diversity in a complex ecosystem. Academic, San Diego, pp 221-238

Kimura DK (1980) Likelihood methods for the von Bertalanffy growth curve. Fish Bull 77:765-776

Krebs JR, Davies NB (1978) Behavioural ecology: an evolutionary approach. Blackwell Scientific, Oxford

MacArthur RH, Pianka ER (1966) On optimal use of a patchy environment. Am Nat 100:603-609

Meekan MG, Wellington GM, Axe L (1999) El Nino-Southern Oscillation events produce checks in the otoliths of coral reef fishes in the Galápagos Archipelago. Bull Mar Sci 64:383-390

Meekan MG, Ackerman JL, Wellington GM (2001) Demography and age structures of coral reef damselfishes in the tropical eastern Pacific Ocean. Mar Ecol Prog Ser 212:223-232

Nagy KA, Shoemaker VH (1984) Field energetics and food consumption of the Galapagos marine iguana, Amblyrhynchus cristatus. Physiol Zool 57:281-290

Ochi H (1985) Temporal patterns of breeding and larval settlement in a temperate population of the tropical anemonefish, Amphiprion clarkii. Jpn J Ichthyol 32:248-257

Palacios DM (2002) Factors influencing the island-mass effect of the Galapagos Archipelago. Geophys Res Lett 29:2134-2137

Robertson DR (1991) The role of adult biology in the timing of spawning of tropical reef fishes. In: Sale PF (ed) The ecology of fishes on coral reefs. Academic, San Diego, pp 356-386

Robertson DR, Green DG, Victor BC (1988) Temporal coupling of production and recruitment of larvae of a Caribbean reef fish. Ecology 69:370-381

Robertson DR, Petersen CW, Brawn JD (1990) Lunar reproductive cycles of benthic-brooding reef fishes reflections of larval biology or adult biology? Ecol Monogr 60:311-330
Rubenstein DR, Wikelski M (2003) Seasonal changes in food quality: a proximate cue for reproductive timing in marine iguanas. Ecology 84:3013-3023

Sanford E (1999) Regulation of keystone predation by small changes in ocean temperature. Science 283:2095-2097

Stearns SC (1992) The evolution of life histories. Oxford University Press, New York

Steneck RS, Dethier MN (1994) A functional-group approach to the structure of algal-dominated communities. Oikos 69:476 498

Thresher RE (1984) Reproduction in reef fishes. T.F.H. Publications, Neptune City, NJ

Tyler WA, Stanton FG (1995) Potential influence of food abundance on spawning patterns in a damselfish, Abudefduf $a b$ dominalis. Bull Mar Sci 57:610-623

Wellington GM, Strong AE, Merlen G (2001) Sea surface temperature variation in the Galapagos Archipelago: A comparison between AVHRR nighttime satellite data and in situ instrumentation (1982-1998). Bull Mar Sci 69:27-42

Werner EE, Hall DJ (1974) Optimal foraging and size selection of prey by bluegill sunfish (Lepomis macrochirus). Ecology 55:1042-1052

Werner EE, Gilliam JF, Hall DJ, Mittelbach GG (1983) An experimental test of the effects of predation risk on habitat use in fish. Ecology 64:1540-1548

Wikelski M, Wrege PH (2000) Niche expansion, body size, and survival in Galapagos marine iguanas. Oecologia 124:107-115

Wootton RJ (1990) Ecology of teleost fishes. Chapman and Hall, London

Zar JH (1999) Biostatistical analysis, 4th edn. Prentice Hall, Upper Saddle River, NJ 